\title{
The educational role of language in experiences with virtual reality
}

\author{
Slađana Marić \\ University of Novi Sad, Faculty of Philosophy, Serbia; s.maric.ff.uns@gmail.com
}

\begin{abstract}
This paper focuses on developing a wider understanding of 'the educational role of language' in the digital age. Features of virtual reality and the relationships with diverse learning settings are closely explored in a brief literature review of $V R$ application in education. In addition, a small qualitative case study was conducted through an online survey posted on Facebook "VR in Education" pages and groups - directed towards participants actively engaged in current issues about virtual reality in educational processes. Data included thirteen completed questionnaires from participants, from eleven different countries, that have experienced learning and/or teaching in virtual reality contexts or are focusing their work and research on issues on immersive virtual environments in education. The qualitative method of content analysis of data received through questionnaires was applied, and the results were presented through thirteen short stories of learning and/or teaching experiences and reflections on the use of virtual reality immersive technologies in the learning and teaching processes. A special focus in the analysis of these stories was directed towards the possible interconnections in learning and teaching content of other subjects through English (as a first, second or foreign language) or other languages.
\end{abstract}

Keywords: educational landscape, digital learning environments, language-learning experience, language spaces, virtual reality $(V R)$

\section{Introduction}

For decades educators and teachers are trying to incorporate new alternative ways of using technology in learning and provide learning environments that will offer realistic contemporary learning experiences and real-life language learning experiences. Weiss (2006: 2) recalling on the definition by Ursula Franklin in "The Real World of Technology" (1990), acknowledges that technology should not be regarded as more than "a toll" in education, but "a practice, or a system that involves organisation, procedures, symbols, new words, equations, and most of all, a mind set".

The workforce of the $21^{\text {st }}$ century is increasingly imposing a demand on education today by focusing on skills such as creativity, empathy, critical thinking, and technological or digital and media literacy (Hu-Au \& Lee 2017). Learning is "the process whereby knowledge is created through the transformation of experience" (Kolb 1984, as cited in Weiss 2006: 4). Almost a decade ago, Passig (2009: 291) stated that virtual reality "is poised to change the way we demonstrate ideas and familiarise children with some difficult to explain knowledge", and it has, to some extent. New virtual reality learning environments, as part of the increasingly complex landscape of digital technology, are creating new possibilities for different experiences and learning paths on different levels of formal education, informal learning and professional development. In this paper the focus will be on developing a wider understanding of 'the educational role of language' in the digital age. Features of virtual reality and the relationships with diverse learning settings are closely explored through a literature review of VR application in education, and the results of a small qualitative case study, conducted as an online survey via a post on Facebook "VR in Education" pages and groups.

\section{Learning in the digital age: virtual reality in education}

Virtual reality (VR) is "a part of a larger family of technology-mediated experiences involving a varying degree of blends of reality with virtual components. Related areas along this continuum of reality and virtuality are augmented reality and mixed reality" (Hu-Au \& Lee 2017: 215)6. It is also defined as "an immersive, computer-enabled technology that replicates an environment and allows a simulation of the

\footnotetext{
${ }^{6}$ Augmented realty (AR) system allows for combining, supplementing, projecting or superimposing virtual 2D or 3D objects (or information) placement and orientation on real world objects or within the real world. In practice it the main purpose of using AR has been for explaining a topic of interest as well as providing additional information (Bacca, Baldiris, Fabregat, Graf \& Kinshuk 2014). Mixed reality allows merging of the real and virtual worlds to produce new environments and visualizations where physical and digital objects co-exist and interact in real time. It is a hybrid of reality and virtual reality, encompassing both augmented reality and augmented virtuality through immersive technology.
} 
user to be present and interact in that environment" (Lloyd, Rogerson \& Stead 2017: 222). Virtual Reality or "artificial reality", "virtual/artificial worlds" represents "a fully-immersive, absorbing, interactive experience of an alternate reality through the use of a computer structure in which a person perceives a synthetic (i.e., simulated) environment by means of special human-computer interface equipment and interacts with simulated objects in that simulated environment; also, several persons can see one another and interact in a shared synthetic environment (Inoue 2008: 2)". Virtual Reality Learning Environments (VRLEs) are "interactive learning environments that favour the immersion and allow to simulate a realistic environment in which users can perform specific tasks" (Curcio, Dipace \& Norlund 2016: 1). Inoue (2008: 1) notes that educational virtual reality (EduVR) learning environment "is not only an interactive multimedia tool but also a learning environment that is extremely close to reality".

The key to the learning process in the virtual world is the embodied avatar through which students interact with the environment, embodied virtual agents, or real people. The embodied "self" via avatar is not the separation of real-world "Self"; instead, it is the link between the real "self" mind/cognition and the virtual "body" enabling immersion and learning (Pasfield-Neofitou, Huang \& Grant 2015: 723). According to Nooriafshar, Williams and Maraseni (2004: 3) virtual reality used in education were recognised as the most convenient in situations where "access to the real object or environment is hard or impossible", where "using the actual objects is unsafe or poses a health hazard for the user", and "obtaining and experimenting with the real object is too expensive."

A diversity of materials can be provided in these novel interactive learning or entertainment environments, where students simultaneously read or listen to and interpret images, graphics, animation, text and sound, connecting perception and instant action. In the findings published in the Global Nomads Group toolkit for teachers "Virtual Reality for The Classroom" (2018), three types of VR are distinguished: (1) Full Immersion, Computer Generated (CG) VR; (2) Cinematic VR; (3) Desktop VR. The first type includes Head-Mounted Displays (HMDs) (e.g. Oculus Rift, HTC Vive) that in the entertainment and educational contexts can offer 3D computer animation, field of vision (FOV) of 110 degrees, and "full interactivity" with the 3D environment - through fibre-optic gloves, controllers, camera sensors, and eye-tracking systems. The second type is most common in film making and media and known as "360-degree videos". The third type is currently the most common and affordable in major educational settings. It is the least immersive option, as it uses a monitor of a standalone device (tablet/computer) to display content and allow interactivity with the environment, largely depending on the outside controls for interacting (mouse, keyboard, touch-screen). Virtual reality, as a computing platform, offers the possibility to eliminate the indirect control of the mouse, keyboard or a display. Therefore, the interactions usually are based on movement sensors, eye tracking or simply the voice or speech of the person wearing VR. It is important to understand VR as something apart from "only engaging and interacting with pre-made 3D objects", as learners can now interact with the sound as well (narration, sound effects and music). Furthermore, they can engage in creating VR content.

In one of the earliest literature reviews (research up until the end of $20^{\text {th }}$ century) on virtual reality environments in computer assisted language learning (CALL), Klaus Schwienhorst (2002), explored the concept of learner autonomy through three different approaches: 1) an individual-cognitive (Kelly), emphasizing learner awareness; 2) a social-interactive (Vygotsky), emphasizing interaction and peer collaboration and 3) an experiential and experimental (Bruner), emphasizing active participation of the learner in the learning process, arguing that "VR concepts can support these approaches by looking at VR theorists and empirical CALL research using VR". Virtual reality continued to be in the focus of educational research (Nooriafshar, Williams \& Maraseni 2004, Weiss 2006, Inoue 2008, Passig 2009, Dutra Piovesan et al. 2012, Bacca et al. 2014, Curcio, Dipace \& Norlund 2016, Hu-Au \& Lee 2017, Stojšić, Ivkov-Džigurski \& Maričić 2018), and language learning in particular, providing a practical and theoretical insights into to the capabilities of virtual reality in foreign language education (Szabó 2011, Grant, Huang \& Pasfield-Neofitou 2013, Repetto 2014, Lin \& Lan 2015, Pasfield-Neofitou, Huang \& Grant 2015, Chen \& Chen 2016, Lloyd, Rogerson \& Stead 2017, Bonner \& Reinders 2018, Bambury 2018, Peixoto et al. 2019).

As noted by Szabó (2011: 67) "improving achievement is one of the common aims of parents and teachers at all educational levels, from kindergarten to secondary and higher education". This is in most 
cases very dependent on the knowledge and skills of language or languages, where "we look at people and frequently describe them in terms of how much they speak, how extensively they read, how well they write or how attentively they listen (Daszkiewicz, Wenzel \& Kusiak-Pisowacka 2018: 18). In the context of learning languages, the importance of authentic foreign language environment remains the main goal in providing quality language learning experiences, not forgetting the issue of high cost for obtaining this environment (Chen \& Chen 2016: 23). As noted by Grant, Huang and Pasfield-Neofitou (2013) research into learning in virtual environments indicates that anxiety in language performance can be reduced in such learning environments, although, learners may need to develop a range of digital or technical skills in using VR to facilitate interaction. One of the preliminary results confirmed that "students found the virtual environment less stressful in terms of language use".

According to Steve Bambury (2018) virtual reality has the potential "to redefine the way students can learn languages in a variety of ways", through (1) using live AR translation; (2) live tutoring and language labs inside virtual worlds; (3) Al - Artificial Intelligence integration with AR and VR (e.g. Mondly); (4) 360 video scenarios with voice-recognition (e.g. ImmerseMe) and (5) "language-based memory places" or virtual spaces that learners can build and include 3D models, text boards, images, GIFs, and a "living dictionary" with audio recordings of the vocabulary associated with each object, or interactive scenes for review or revision of key conversational language (e.g. CoSpaces Edu).

The teaching and learning methods and approaches with VR can be regarded as inherited from the preVR pedagogical era and are now in the state of experimental improvement, extension or transformation, providing space for the new pedagogical approaches to emerge. Students are learning through:

- "going on a virtual field trip";

- "bringing science to life";

- "recreating real-life structures in virtual space";

- "creating fictional spaces";

- "solving mysteries";

- "becoming the story through role-playing games", etc.

In the most recent published research on VR in education, Stojsic, Ivkov-Dzigurski and Maricic (Stojšić, Ivkov-Džigurski \& Maričić 2018: 365) used a reflective writing as a method for "triggering teachers in-depth thinking about their teaching practice" on four main themes: support, integration, perceived impact and benefits, and barriers and limitations of $V R$ in teaching. They conducted their research in the context of formal education in the Republic of Serbia with a sample of 12 teachers as participants in this qualitative study. These teachers reported on their using of mixed-virtual reality and augmented reality through group learning activities or in project work, where students bring their own digital media devices $\left(\mathrm{BYOD}^{7}\right)$ and use them in specific learning tasks for specific learning targets. The findings from the research of Stojsic at al. (2018), indicate that teachers used different VR experiences in order to match the content with the curriculum and lesson goals, but also combined VR in teaching with other digital tools (videos, podcasts, wikis, blogs or forums, and mobile apps).

\section{Research methodology \\ The research strategy}

Previous academic research exists regarding the 'the educational role of language', as well as, the implementation and the role of VR in Education, in general and in specific subject areas, such as learning languages or learning English language as a second or foreign language. As such, the proposed research case study took the form of new research, merging the two existing research subjects, therefore, regarding to the educational role of language in experiences with virtual reality.

\section{The aim of the research}

The aim is of this paper is to develop a wider understanding of 'the educational role of language' in the digital age. We explore in what contexts of learning and/or teaching participants used virtual reality. In the 
field of our research interest are the participants' reflections on the use of immersive technologies in the learning and/or teaching processes:

1) the VR environments used;

2) the language and its role in learning in such environments,;

3) the possible examples of meaningful and engaging, socio-linguistically and culturally loaded materials use in learning and teaching;

4) the features of virtual reality and the relationships with diverse learning settings.

\section{Data collection method and tools}

In this survey, an original online questionnaire was used in gathering data on current uses of VR in learning and teaching settings. The questionnaire ${ }^{8}$ was designed in English language in the Google Forms, where the questions were with multiple answer options, closed and open-ended (Appendix 1).

The population to which the inquiry was addressed, included speakers of English language as individuals with experience in learning and/or teaching in virtual reality contexts or focusing their work and research on issues of immersive virtual environments in education.

The questionnaire was distributed, from December $2^{\text {nd }}$ to $4^{\text {th }}, 2018$, as a post on Facebook pages and within groups focusing on immersive virtual environments in education: (1) VIRTLANTIS (group); (2) Virtual Worlds Best Practices in Education (group); (3) VR in Education (group); (4) VR Education. Virtual Reality and Education. Realidad Virtual y Educación (group); (5) Virtual Worlds: Best Practices in Education (page); (6) Music Education Virtual Reality - MEVR (page); (7) Virtual Reality for Education (page); (8) Virtual World Language Learning's Page and (9) VR All Art.

\section{The selection of the sample}

The method of non-probability - purposive sampling (Cohen, Manion \& Morrison 2007: 114) was used to develop the sample of the research under discussion. Purposive sampling was used in accessing 'knowledgeable people' or those who may have specific or in-depth knowledge about particular issues, based on their professional role, access to networks, expertise or experience, all with the aim of acquiring "in-depth information from those who are in a position to give it" (Cohen, Manion \& Morrison 2007: 114). The sample included data from 13 completed questionnaires by individuals actively engaged in issues in the field of "VR in Education" discussed in specific groups or pages on social media site Facebook. These 13 individuals (from 11 different countries) were speakers of English and other languages, with experience in learning/teaching in virtual reality contexts or focusing their work and research on issues of immersive virtual environments in education (e.g. teachers, teacher trainers, English language teachers, professor trainer, researcher, VR developers, student and a senior citizen).

\section{The type of data analysis}

The qualitative content analysis (Cohen, Manion \& Morrison 2007) was used in analysing the gathered data. The process of qualitative content analysis of answers from the questionnaire included several processes:

- coding (defining the main units of content analysis (text) and selecting the instruments for noting the units of content analysis, indicators - word, phrase, sentence, etc.);

- categorisation of data;

- examination of the interconnectedness of units of analysis (categories).

The results were presented through thirteen short stories of learning and/or teaching experiences with virtual reality from thirteen participants. Stories follow the same structural organisation of text into several sections:

- demographic information gathered as a result of the survey - information about the participant (role student, teacher, developer, other);

- previous usages of VR (type of VR, brand);

\footnotetext{
8 Link to the survey http://tiny.cc/215f1y or https://docs.google.com/forms/d/e/1FAlpQLSdS0eJLq7D Fks5Nb1ozBHj5CX3TGcrv0vFy4R8io6bWT_g10/viewform. The questionnaire was piloted in November 2018.
} 
- information about the VR content used (theme, language, sound) and the aim or purpose of use;

- VR preferences, future intentions for VR usage.

A special focus in the analysis of these stories is directed towards the possible interconnections in learning and teaching content of other subjects through English (as first, second or foreign language) or other languages.

\section{Research limitations}

This study has two main limitations, often associated with educational qualitative research, the overall number of participants (rather small data sample of 13 questionnaires), and generalisation based on the data and results from the purposive sampling as rather limited. The third limitation might be the time allocated for the survey.

\section{Results}

The number of participants that responded to the questionnaire was in total 13 . The participants were from many different countries (England/Sweden, Belgium, Finland, Italy, India, UAE, UK, USA, and two from New Zealand and Ukraine). The participants were: four teacher trainers, two English language teachers, two teachers, one student of master studies, researcher, VR developer, professor trainer, and one senior citizen.) Based on the information gathered through the posted questionnaire, the results were presented through thirteen short stories of learning and/or teaching experiences with virtual reality. Stories follow the same structural organisation of text into four main sections (information about the participant, previous usages of VR, information about the VR content used and the aim or purpose of use, VR preferences, and future intentions for VR usage), with a special focus directed towards the possible interconnections in learning and teaching content of other subjects through English (as first, second or foreign language) or other languages.

Story 1 - Teacher trainer (England/Sweden) using VR in teaching in the virtual classroom through virtual worlds for 5-10 years. Experienced a VR in the English Language lesson or lecture. VR used: Aris and Second Life ${ }^{9}$. VR "has been very successful - running a course with VR for the $24^{\text {th }}$ term in a row in the spring" $[P 1]^{10}$. The content was in English, and the participant speaks English as the first language. Language in VR was used for listening and speaking (interacting with the program or other participants). Language is not seen as an obstacle in the personal VR learning experience. The participant used VR to run a language course. In the VR environment for learning/teaching, there was sound (music, songs, sound effects, speech, conversation, etc.). The content preferred in learning/teaching with VR is spoken business English. The program or app the participant likes the most in learning/teaching is Second Life. In the future, the participant would like to experience VR in the same teaching context " $28^{\text {th }}$ cycle of the course" and retire after that.

Story 2 - English language teacher (Ukraine) using VR in personal learning through virtual worlds for 2 3 years. Experienced VR as part of the self-initiated learning (not for teaching). Not experienced VR in the school or faculty lesson in a specific subject area. The content of learning was in English, and the participant speaks English as the second or a foreign language (first language is Ukrainian). Language in VR was used for reading, listening to a story, and listening and speaking (interacting with the program or other participants). Language is not seen as an obstacle, but as an important factor in the personal VR learning experience. In the VR environment for learning/teaching, there was sound (speech and conversation). The participant "really enjoyed having conversations, meeting people from different countries". The program or app the participant likes the most in learning/teaching is Second Life. In the future, the participant would like to experience some new opportunities for language practice.

Story 3 - Senior citizen (Finland) using virtual reality (VR) in learning in a virtual classroom, within virtual worlds, for 5-10 years. Not experienced VR in the school or faculty lesson in a specific subject area. Used only The Second Life, a free 3D virtual world. VR experience "creates a relaxed environment, comfortable"

\footnotetext{
9 Second Life - an "open social virtuality" that allows the users "to immerse themselves in a wide variety of social contexts, participating in individual and group activities" (Lin \& Lan 2015: 486).

${ }^{10}[\mathrm{P} 1]$ - citation of the answer from the questionnaire by Participant No. 1
} 
[P3]. The content of learning was in English, and the participant speaks English as the second or a foreign language. Language in VR was used for listening and speaking (interacting with the program or other participants). Language is not seen as an obstacle, but as an important factor in the personal VR learning experience of learning English and Spanish language. In the VR environment for learning/teaching, there was sound (speech). The content this participant prefers in learning with VR is learning languages. The program or app the participant likes the most in learning/teaching is Second Life. Considering the future, the participant notices that "communities in VR are already quite creative".

Story 4 - Researcher (Italy), an expert in the field of VR. Using VR headsets (such as Google Cardboard) in teaching in the physical classroom for one year. Tried VR in the Science lesson or lecture. VR brands used: Google, CoSpaces. For this researcher, VR "is valuable for SEN" [P4]. The content was in Italian. Language in VR was used as a text for reading, and for reading and answering quick questions (multiple choice answers). Language is not seen as an obstacle, but as an important factor in the VR learning experience. In the VR environment used for learning/teaching there was some background music. The contents preferred in learning/teaching with VR are science and arts. The program or app the participant likes the most in learning/teaching is CoSpaces. In the future, the participant would like to experience more VR content. The comments were: "VR is useful and powerful to get attention and engagement; very good also for storytelling and coding".

Story 5 - Teacher trainer (USA) using VR (Google Expeditions and Merge cube), in teaching in the physical classroom for $2-3$ years. Tried VR in Biology lesson or lecture. VR brand used: Merge and Google. This researcher is "using more AR because of tablets instead of phones/goggles, apps are expensive" [P5]. The content was in English (the participant's first language). Language in VR was used as a text for reading. Language is not seen as an obstacle, but as an important factor in the VR learning experience. In the VR environment used for learning/teaching there was no sound. The content preferred in learning/teaching with VR is the content from Merge or Google Expeditions, and these are also the programs or apps the participant likes the most in learning/teaching. In the future, the participant would like to experience more "VR science content and other contents areas" [P5].

Story 6 - Teacher (New Zealand) using VR headsets in teaching in the physical classroom for $2-3$ years. Tried VR in Biology and Science lessons or lectures. VR brand used: HTC Vive and Google Cardboard. The content was in English (the participants' first language). Language in VR was used for listening and speaking (interacting with the program or other participants). The participant thinks that languages in not important in the VR experience. In the VR environment used for learning/teaching there were some sound effects "that in particular make the experience more immersive" [P6]. The content preferred can be characterised as "keep talking and nobody explodes, plank style games, any realistic space/physics /biology simulation" [P6]. The participant would like to be able "to create personal bespoke experiences" - "as there are a lot of possibilities and software companies are not aware of them". The participant commented that VR is "very powerful but costs need to come down. Full immersive VR is not likely to become mainstream until there are 'must have' applications that justify 1:1 teaching".

Story 7 - Teacher trainer (UAE), an expert in the field of VR. Using VR in teaching and learning in both the physical and virtual classroom for $4-5$ years. The types of VR used are: $360^{\circ}$ videos on desktop computers, tablets and mobile device screens, VR headset such as Google Cardboard, VR headset designed for education $\mathrm{K}-12$, VR devices for gaming and Virtual Worlds. Experienced VR in the English Language lessons, History, Geography, Mathematics, Biology, and Media Literacy. VR brands used: "most of them". The content was in English, and the participant speaks English as the first language. Language in VR was used in different ways depending on the app. Language is not seen as an obstacle in the personal VR learning experience, but as an important factor in learning with VR. In the VR environment for learning/teaching, the presence of sound (music, songs, sound effects, speech, conversation, etc.) "varies from app to app". The content preferred in learning/teaching with VR is History. In the future, the participant would like that "wireless 6DOF headsets, multi-person VR becoming more accessible in schools". He is the creator of a website dedicated to learning and teaching with VR.

Story 8 - VR developer (Ukraine), an expert in the field of VR - developer program. Used VR devices for gaming it in both, physical and virtual classrooms for $2-3$ years. Tried VR in school subjects such as 
Robotics/programing. The content was in Ukrainian. Language in VR was used as a text for reading and for listening to a story. Language is not seen as an obstacle in the personal VR learning experience, but as an important factor in learning with VR. In the VR environment for learning/teaching, there was sound (music, songs, sound effects, speech, conversation, etc.). The content preferred in VR is educational content. In the future, the participant would to experience "simulation of the flight to Mars".

Story 9 - English language teacher (UK) using VR in teaching in the physical classroom for 6 months. Types of VR used: 360 degrees videos on desktop computers, tablets and mobile device screens, VR headset such as Google Cardboard, VR headset designed for education K - 12, VR devices for gaming and Virtual Worlds. Tried VR in English Language and Biology lessons. Brands used: Oculus and Google. The content was in English, and the participant speaks English as the first language. Language in VR was used as a text for reading, for listening to a story, for listening and speaking (interacting with the program or other participants) and for reading and answering quick questions (multiple choice answers). Language is not seen as an obstacle in the personal VR learning experience. The participant used VR to learn and teach language. In the VR environment for learning/teaching, there was sound (music, songs, sound effects, speech, conversation, etc.). In the future, the participant would like to experience VR "remote 360 3D live access to learning".

Story 10 - Teacher trainer (US) using VR headset for 6 months in order to be able to train or teach other teachers in using it. No experience in specific school or faculty subjects through VR content. Brand used: Lenovo. The content was in English (first language of the participant). Language was used as a text for reading, and for listening and speaking (interacting with the program or other participants). Language is not seen as an obstacle in the personal VR learning experience. In the VR environment for learning/teaching, there was sound (music, songs, sound effects, speech, conversation, etc.). The content preferred is learning with "virtual field trips". In the future, the participant would like "to see VR used for kids with emotional problems" [P10].

Story 11 - Professor trainer (Belgium) using VR in teaching in the physical classroom with VR headset 1 5 months. Experienced VR in the Pedagogy and didactics lecture. VR brands used: Roundme, Panopto and Google cardboard. The experience of this participant was the following: "It is hard to know where to start in VR when you're new to it, but after convincing myself to just start, and some ups and downs, it really has a positive effect on the learning goals. Key, is to research what to do and don't do with VR in education" [P11]. The content was in Dutch. Language was used for listening to a story. Language is not seen as an obstacle in the personal VR learning experience. In the VR environment for learning/teaching, there was no sound. The content preferred in learning/teaching with VR is "content where people have to experience the atmosphere in a certain situation of have to pay attention to multiple focus-points" [P11]. The program or app the participant likes the most in learning/teaching is Panopto. In the future, the participant would like to experience VR with "more interaction with other users" [P11].

Story 12 - Teacher (India) using VR headset designed for education $\mathrm{K}-12$ in teaching in the physical classroom for $2-3$ years. Experienced VR in History and Geography. VR brand used: View master. For the participant, VR experience is "an enriching experience for students without having to travel and provides opportunities for students to interact and learn s wide variety of topics" [P12]. The content experienced was in English, and the participant speaks English as the first language. However, the teacher used VR content with "no language at all" [P12]. The teacher does not see language as an obstacle in the personal VR learning experience, but as an important factor in learning with VR - "because when students are interacting with the scene, teachers get the opportunity to reflect on students' learning" [P12]. In the VR environment for learning/teaching, there was sound. The content preferred in learning/teaching with VR is: environmental science, history, geography, and science. The programs or apps that the teacher likes the most in learning/teaching are: Merge cube and Google expeditions. In the future, the participant would like his students have "more opportunities to interact with each other and content" [P12].

Story 13 - MA student (New Zealand) using VR - Google Cardboard for learning through play. Not experienced learning with VR in school or faculty subject areas. The content experienced was in English (first language). The language was present in the menu, audio narration and explanations, and it is not seen as an obstacle in the VR learning experience but was not regarded as important in learning. There was 
sound in the VR content experienced. For the participant, the virtual reality to be experienced in future are Oculus Quest, games and travel videos.

\section{Concluding discussion}

In this small qualitative study regarding the experience of participants (from 11 different countries) as teachers, teacher trainers, English language teachers, professor trainer, researcher, VR developers, student and a senior citizen, we managed to capture some reflections on the use of immersive technologies in the learning and teaching processes. This study has several limitations, the number of participants was small, the time allocated was 3 days, and the questionnaire was posted on the pages and groups of users on one social media space focusing on VR in education and arts, and therefore generalisation based on the results is rather limited. However, these limitations are often associated with educational qualitative research. What distinguishes this small-scale research is the focus on the role of language in the learning and teaching experiences with VR.

The participants used VR in the contexts of learning and teaching in the physical classroom (6), virtual classroom (2), both, physical and virtual classrooms (3), and not in a classroom, but as self-initiated learning (at home/school/work) (2). The type of VR used was in most cases VR headset such as Google Cardboard (4), Virtual Worlds (3), $360^{\circ}$ video on desktop computers, tablets and mobile phones (2), VR headset designed for education K -12 (1), VR devices for gaming (1), "all the above mentioned" (2). The brands that were used by the participants were: Aris, Second Life, Google Cardboard, CoSpaces, Merge, HTC Vive, Oculus rift/GO, Lenovo, Roundme, Panopto, and View master.

There were participants that have been using such technology for: only up to five months (1), 6 months (2), one year (1), $2-3$ years (5 participants), $4-5$ years (1), and $5-10$ years (2). Regarding the content, participants have tried VR in many school lessons or faculty lectures in Biology, English Language, Geography, Science, but also in Mathematics, Media Literacy, Robotics/programing, and Pedagogy and didactics.

The participants experience with VR was regarded as "very successful", "very positive", "enriching experience", "learning in a relaxed environment, comfortable", "valuable for SEN", "VR really has a positive effect on the learning goals", and "fun".

The language in VR was English - as the first language to participants (8; 61.5\%), English as a second/third/foreign language $(2 ; 15.4 \%)$, Italian $(1 ; 7.7 \%)$, Dutch $(1 ; 7.7 \%)$, and Ukrainian $(1 ; 7.7 \%)$. Language was used in most cases in one or a combination of the following types: as a text for reading (6; $46.2 \%)$, for listening and speaking (interacting) $(6 ; 46.2 \%)$, for listening to a story $(4 ; 30.8 \%)$, there was no language at all $(1 ; 7.7 \%)$, "varies from app to app" $(1 ; 7.7 \%)$, "in the menu, audio narration" $(1 ; 7.7 \%)$. Language was perceived as not being an obstacle in the VR learning experience by all the participants (13; $100 \%)$. Eleven participants stated that language is important in the VR learning experience, while two stated that it may not be important. Those that agree add that language was: 1 ) the main subject of learning; 2) very important; 3) main means of communication in a training course and 4) important for allowing students to interact and teachers to reflect on students' learning.

The content preferred in learning/teaching with VR was: spoken business English, languages (English, Spanish), science, arts, physics, biology, geography, history, education content in general, virtual field trips, "content where people have to experience the atmosphere in a certain situation", environmental science, etc. Tools and programs or applications that participants recommended were: Second Life, Merge cube, Google expedition, Cospaces, etc.

The participants in this research would like to experience in future the VR becoming more accessible in schools (e.g. wireless 6DOF headsets, multi-person VR, remote 360 3D live access to learning), as well as seeing more content available, such as, "simulation of the flight to Mars" [P8], more VR science content, content in travel, more content that provides opportunities for interaction, uses of VR in solving emotional problems, etc. Furthermore, virtual reality is regarded as "useful and powerful to get attention and engagement" [P4] but still expensive to become part of mainstream education.

Possible advantages of using educational VR or VR for educational purposes:

- VR can make the initial learning more interesting and fun; 
- provide opportunities to learners for self-directed, lifelong learning;

- provide learners with the feeling of immersion;

- new and inventive ways to teach and engage students in learning;

- provide the learner with the sense of physical imagination;

- offer opportunities for intuitive interactions;

- more content in open access that can meet the needs of learners or an individual instructor's curriculum needs;

- help in not making race and gender barriers through visiting different countries and experiencing different cultures (Inoue 2008: 1);

- experiencing things that cannot be experienced in the real world, events and places in the past or future.

It is always good to keep in mind the notion that "education can be seen as a discovery, exploration and observation process, besides the eternal construction of the knowledge" and virtual reality can offer such education through immersion, interaction and involvement; "it presents an opportunity of learning with a real situation, but artificially created, facilitating the visualisation and the interaction sensation with the study focus" (Dutra Piovesan, Maria Passerino \& Soares Pereira 2012). In conclusion, VR is re-shaping the socio-cultural life, educational or learning processes in the $21^{\text {st }}$ century, as learning "centres on experiences", where visual and auditory content (images, language in all its forms, music, sound) are key factors in shaping both the message and the participants. Furthermore, "the ability to create empathy in students and to change perspectives" is regarded as one of the strongest arguments for VR as a learning tool (Hu-Au \& Lee 2017: 221).

\section{Acknowledgements}

This research was conducted by Dr Sladana Maric, Research Assistant at the Faculty of Philosophy of the University of Novi Sad (Serbia), engaged within the project titled "Digital Media Technologies and SocioEducational Changes" (III47020) funded by the Ministry of Education, Science and Technological Development of the Republic of Serbia".

\section{Conflict of interest statement}

The author declares that the research was conducted in the absence of any commercial or financial relationships that could be construed as a potential conflict of interest.

\section{References}

Bacca, J., Baldiris, S., Fabregat, R., Graf, S. \& Kinshuk. (2014). Augmented Reality Trends in Education: A Systematic Review of Research and Applications. Educational Technology \& Society, 17 (4), 133-149.

Bambury, S. (2018). Five ways to use AR/VR for language learning, blog post, VirtualiTeach, October 23, 2018, https://www.virtualiteach.com/single-post/2018/10/23/Five-ways-to-use-ARVR-for-language-learning

Bonner, E. \& Reinders, H. (2018). Augmented and Virtual Reality in the Language Classroom: Practical Ideas. Teaching English with Technology, 18 (3), 33-53.

Chen, X. \& Chen, M. (2016). The Application of Virtual Reality Technology in EFL Learning Environment in China. $6^{\text {th }}$ International Conference on Sensor Network and Computer Engineering (ICSNCE 2016), 23-26.

Cohen, L., Manion, L. \& Morrison, K. (2007). Research Methods in Education, Sixth edition. New York: Routledge.

Curcio, I. D. D., Dipace, A. \& Norlund, A. (2016). Virtual realities and education. REM - Research on Education and Media, 8 (2), 60-68.

Daszkiewicz, M., Wenzel, R. \& Kusiak-Pisowacka, M. (2018). Educational Role of Language Skills. Wydawnictwo Uniwersytetu Gdańskiego/Gdańsk University Press.

Dutra Piovesan, S., Maria Passerino, L. \& Soares Pereira, A. (2012). Virtual Reality as a Tool in the Education. IADIS International Conference on Cognition and Exploratory Learning in Digital Age (CELDA 2012), 295-298.

Global Nomads Group (2018). "Virtual Reality for The Classroom" toolkit for teachers, http://gngvrlab.brandcast.com/gng-vr-101-02d.pdf

Grant, S., Huang, H. \& Pasfield-Neofitou, S. (2013). Language Learning in Virtual Worlds: The Role of Foreign Language and Technical Anxiety. Journal of Virtual Worlds Research, 6 (1), 1-11. 
Hu-Au, E. \& Lee, Joey J. (2017). Virtual reality in education: a tool for learning in the experience age. International Journal Innovation in Education, 4 (4), 215-226.

Inoue, Y. (2008). Concepts, Applications, and Research of Virtual Reality Learning Environments. International Journal of Social Sciences, 2 (1), 1-7.

Lin, T. \& Lan, Y. (2015). Language Learning in Virtual Reality Environments: Past, Present, and Future. Educational Technology \& Society, 18 (4), 486-497.

Lloyd, A., Rogerson, S. \& Stead, G. (2017). Imagining the Potential for Using Virtual Reality Technologies in Language Learning. In M. Carrier, R. M. Damerow \& K. M. Bailey (Eds.), Digital Language Learning and Teaching: Research, Theory, and Practice. (pp. 222-234). Routledge Taylor \& Francis.

Nooriafshar, M., Williams, R. \& Maraseni, T. N. (2004). The use of virtual reality in education. In American Society of Business and Behavioral Sciences (ASBBS) - 2004 Seventh Annual International Conference, 6-8 Aug 2004, Cairns, Australia. pp. 1-13.

Pasfield-Neofitou, S., Huang, H. \& Grant, S. (2015). Lost in second life: virtual embodiment and language learning via multimodal communication. Educational Technology Research and Development, 709-726.

Passig, D. (2009). The Future of Virtual Reality in Education: A Future Oriented Meta Analysis of the Literature. Themes in Science and Technology Education, Special Issue, 269-293.

Peixoto, B., Pinto, D., Krassmann, A., Melo, M., Cabral, L. \& Bessa, M. (2019). Using Virtual Reality Tools for Teaching Foreign Languages, In A. Rocha, H. Adeli, L. P. Reis \& S. Constanzo (Eds.), WorldCIST'19 2019, (pp. 581-588). Springer Nature Switzerland.

Repetto, C. (2014). The use of virtual reality for language investigation and learning. Frontiers in Psychology. 5 (1280). doi: 10.3389/fpsyg.2014.01280.

Schwienhorst, K. (2002). Why virtual, why environments? Implementing virtual reality concepts in computer-assisted language learning, Simulation \& Gaming, 33 (2), 196-209.

Stojšić, I., Ivkov-Džigurski, A. \& Maričić, O. (2018). Virtual Reality as a Learning Tool: How and Where to Start with Immersive Teaching. In L. Daniela (Ed.), Didactics of Smart Pedagogy, (pp. 353-369). Springer, Cham, https://doi.org/10.1007/978-3-030-01551-0_18

Szabó, K. (2011). Virtual Reality for Language Learning: An International On-Line Project. The Second International Conference on e-Learning (eLearning-2011), 29-30 September 2011, Belgrade, Serbia, 67-72.

Weiss, J. (2006). Introduction: Virtual Learning and Learning Virtually. In J. Weiss, J. Nolan, J. Hunsinger \& P. Trifonas (Eds.), The International Handbook of Virtual Learning Environments (pp. 1-33). Springer: Netherlands. 
APPENDIX 1

\section{VR in Education: What is your experience?}

Your participation is voluntary. The answers will be shown in an aggregated form in an article. The aim is to develop the wider understanding in creating opportunities for immersive and interactive learning. This questionnaire is open from December 2 to 4, 2018. Thank you for you participation!

* Required

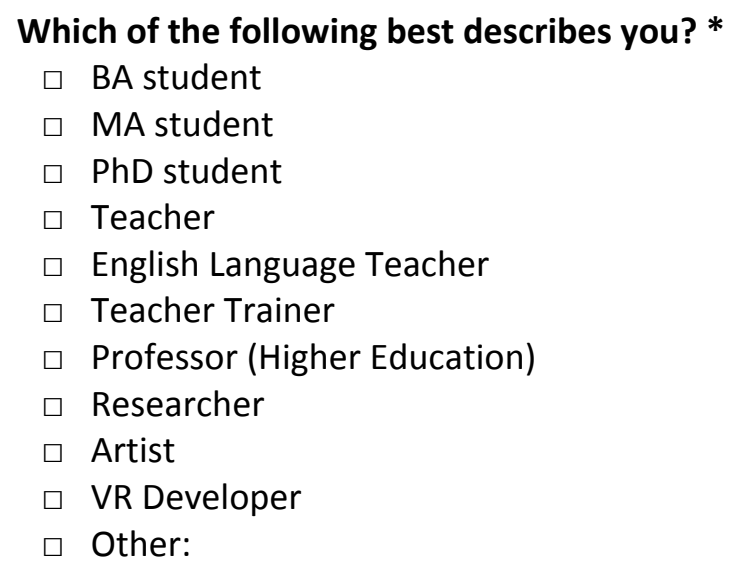

You are from? (Country) *

How familiar are you with the concept of virtual reality (VR)? *

$\square$ I do not know what VR is.

$\square \quad$ I am only slightly aware of what virtual reality is.

$\square$ I am aware what VR is.

$\square \quad I$ am aware what VR is and I am using it in my learning.

$\square \quad I$ am aware what VR is and $I$ am using it in my teaching.

$\square \quad I$ am aware what VR is and I am developing content for others.

$\square \quad \mathrm{I}$ am aware what VR is and I am an expert in this field.

$\square$ Other:

You used VR in learning *

$\square$ in the physical classroom

$\square$ virtual classroom

$\square$ both, physical and virtual classrooms

$\square$ not in a classroom, but as self-initiated learning (at home/school/work)

$\square$ Other:

What type of VR have you used in your learning and/or teaching? *

$\square 360$ degree videos on desktop computers, tablets and mobile device screens

$\square$ VR headset such as Google Cardboard

$\square$ VR headset designed for education $\mathrm{K}-12$

$\square$ VR devices for gaming

$\square$ Virtual Worlds

$\square$ All the above.

$\square$ Other: 
For how long are you using VR in educational purposes? *

$\square \quad 1$ - 5 months

$\square 6$ months

$\square 1$ year

ㄴ 2 -3 years

$\square \quad 4-5$ years

$\square 5$ - 10 years

$\square$ Other:

If you have tried VR in a school lesson or at a faculty lecture, in what subject area(s)? (Check all that apply) *

$\square$ English Language Lessons

$\square$ History

$\square$ Geography

$\square$ Music Lessons

$\square$ Mathematics

$\square$ Biology

口 Media Literacy

$\square$ Non applicable.

$\square$ Other:

Which brand of VR have you used?

Please describe your experience with VR and your opinion of it. *

In what language was the content in the VR environment you experienced? *

$\square$ English - it is also my first language

$\square$ English - I speak English as a second/third/foreign language

$\square$ Chinese

$\square$ Japanese

$\square$ Russian

$\square$ Italian

$\square$ Spanish

$\square$ Greek

$\square$ Arabic

$\square$ Hindi

$\square$ Other:

Language in VR was used *

$\square$ as a text for reading

$\square$ for listening to a story

$\square$ for listening and speaking (interacting with the program or other participants)

$\square$ for reading and answering quick questions (multiple choice answers)

$\square$ there was no language at all

$\square$ Other:

Was the language an obstacle in your VR learning experience? *

$\square$ yes

$\square$ no

$\square$ Other: 
Do you think that language was important in your VR learning/teaching experience? *

Was there any sound in the VR environment you used for your learning/teaching, and did it have any effect on your overall experience in VR? (music, songs, sound effects, speech, conversations, etc.)*

Would you like to share what content you prefer to learn or teach with VR? *

Would you like to share what program or app you like the most in learning and/or teaching with VR?*

What would you like to experience in VR in the future? *

Please share any additional comments or thoughts about VR used for learning and education 